\title{
Demand for health care service and associated factors among patients in the community of Tsegedie District, Northern Ethiopia
}

Tsegay Wellay ${ }^{1 *}$, Measho Gebreslassie ${ }^{1}$, Molla Mesele², Hailay Gebretinsae ${ }^{3}$, Brhane Ayele $^{3}$, Alemtsehay Tewelde ${ }^{1}$ and Yodit Zewedie ${ }^{1}$

\begin{abstract}
Background: Demand-side barriers are as important as supply factors in deterring patients from obtaining treatment. Developing countries including Ethiopia have been focusing on promoting health care utilization as an important policy to improve health outcomes and to meet international obligations to make health services broadly accessible. However, many policy and research initiatives focused on improving physical access rather than focusing on the pattern of health care service utilization related to demand side. Understanding of determinants of demand for health care services would enable to introduce and implement appropriate incentive schemes to encourage better utilization of health care services in the community of Tsegedie district, Northern Ethiopia.

Methods: A community based cross sectional study design was conducted from March1-30/2016 in Northern Ethiopia. Systematic random sampling technique was used to select 423 participants from 2189 patients of the onemonth census. A pretested and standardized semi-structured interviewer administered questionnaire was used to collect the data. The data were entered using Epi-info version 7 and analysed by STATA version 11. Multinomial logistic regression model was used to identify the determinants of demand for health care service.

Results: A total of 423 (with a response rate of 98.3\%) study participants were included in the study. The finding indicates that $72.5 \%(95 \% \mathrm{Cl}=61.6,81.1)$ of the participants demanded modern health care services. The multinomial logistic regression econometric model revealed that perceived severity of illness $(\beta=1.27 ; 95 \% \mathrm{Cl}=0.74,1.82)$, being educated household head $(\beta=0.079 ; 95 \% \mathrm{Cl}=0.96,1.74)$, quality of treatment $(\beta=0.99 ; 95 \% \mathrm{Cl}=0.47,1.5)$, distance to health facility $\beta=1.96 ; 95 \% \mathrm{Cl}=0.11,0.27)$, cost of treatment $(\beta=-1.99 ; 95 \% \mathrm{Cl}=0.85,3,13)$ were significantly and statistically associated with demand for health care service.

Conclusion: This study revealed that in Tsegedie district, majorities (72.5\%) of the patients demanded modern health care service. Distance to health care facility, user-fees, educational status of household, quality of service, and severity of illness were found to be significantly associated with demand for health care service.

Out of pocket, payments should be changed by prepayment schemes like community-based insurance than to depend on user fees and appropriate health information dissemination activities should strengthen to create awareness about modern care.
\end{abstract}

Keywords: Demand of health care, Multinomial logit model, Tsegedie District, Modern health care service

\footnotetext{
*Correspondence: tsegaywellay@gmail.com

${ }^{1}$ Department of Health system, School of Public Health, College of Health

Sciences, Mekelle University, Mekelle, Ethiopia

Full list of author information is available at the end of the article
}

(c) The Author(s). 2018 Open Access This article is distributed under the terms of the Creative Commons Attribution 4.0 International License (http://creativecommons.org/licenses/by/4.0/), which permits unrestricted use, distribution, and reproduction in any medium, provided you give appropriate credit to the original author(s) and the source, provide a link to the Creative Commons license, and indicate if changes were made. The Creative Commons Public Domain Dedication waiver (http://creativecommons.org/publicdomain/zero/1.0/) applies to the data made available in this article, unless otherwise stated. 


\section{Background}

Demand for health care is characterized by the level of actual consumption of an individual incase of facing illness/ injury, this consumption could differ in accordance with demand factors such as income, cost of care, education, social norms and traditions, and the quality and appropriateness of the services provided [1, 2]. It is multidimensional perspective that an individual making a decision in case of illness/injury as far as health care is concerned [3].

Developing countries have been focusing on promoting health care utilization as an important policy to improve health outcomes and to meet international obligations to make health services broadly accessible. However, many policy and research initiatives focused on improving physical access rather than focusing on the pattern of health care service utilization related to demand side [4].

In low-income countries, there is a clear direction to allocate scarce fiscal resources based on a clear understanding of how investments in the heath sector are going to affect demand. Likewise, to understand how changes in the pricing of public services, and investments in quality improvements, are going to affect consumer decisions about whether and where to seek health care $[5,6]$. The occurrence of illness results household welfare loss through increased spending on health or reduced labor productivity and Ethiopia's health sector is highly donor financed nearly to half(48.9\%) and out of pocket $(34 \%)$ of the national health expenditure $[7,8]$.

In developed countries due to the existence of insurance, many health care services has been provided at zero or low monetary prices, and the demand should be infinite or at least extremely high, However, in developing countries context under-utilization is generally more of a concern and lack of supply is considered as the main cause for under-utilization. But even when health facilities are available utilization rate has been low due different barriers from demand side which related to financial cost of treatment, travelling cost and quality of services $[9,10]$.

"The perception of health/illness relates to engaging in preventive behavior and self-care and the importance of self-perceived health status incorporates a clinical framework", "analyzing the social assessment and treatment of disease, health conditions and the social environment of individuals and Study conducted in USA suggested self-perceived health is strongly correlated to the risk of dying" $[11,12]$. studies based on behavioral approaches also called the willingness-to-pay (WTP) methods-have often tended to gross over the distributional implications of the demand estimates and the expenditures financing those public services [13].

As the policy priority area is to improving the health status of the population, there should be investigation in different factors that directly and indirectly affects the demand of the health care services. That is, necessary to analyze the demand for health care services by identifying the factors that affect individuals' decisions to seek health care services and to choose among different providers [14].

Therefore, assessing the determinants of demand for health care services would enable to introduce and implement appropriate incentive schemes to encourage better utilization of health care services in Ethiopia. This will be helpful in identifying specific barriers in seeking health institution conditionally being sick/injury. In addition, to have information on sick individual preferences to different health care service providers in case of visiting modern health institutions.

Since health is an important component of human capital, "good health can substantially increase the capabilities of individuals to perform various activities, including income-generating ones; As a result, individuals demand good health" $[15,16]$.

Health, at the individual level, is mainly influenced by a variety of factors such as unobservable biological determinants, lifestyle choices, non-medical purchased inputs, purchased medical inputs (health care), and various socio-economic factors [17-19]. It is crucial to understand patients' perceptions and expectations of the quality of care, because the perceived quality of health care services often influences the consumption behavior and patterns of health service [20]. "Study conducted in Kenya shows that quality of service offered at health facility significantly affects the demand for health care 6 times increase the likelihood of visiting modern health care service relative to self treatment" [21].

\section{Methods}

The study was carried out in the community of Tsegedie woreda Tigray regional state, North Ethiopia from March 1-30/ /2016.; which is located $1512 \mathrm{~km}$ away from the capital city Addis Ababa. It has estimated total population of 126,608 , of these 63,937 are females and 18,928 are under five children and estimated number of households of the woreda based on the 2007 census conversion factor was about 28,774. Tsegedie has 1 general hospital, 1 primary hospital, 5 governmental health centers, 5 private medium clinics and 13 private drug stores.

\section{Theoretical and empirical framework}

"The neoclassical economic theory of rational consumer and constrained utility maximization is the cornerstone of modern health care demand analysis. In this paradigm, people are assumed to drive utility directly from the health obtained from medical services. The model is based on the idea that 'an individual choose the outcome that maximizes the utility gained from the choice" [22]. "This implies that given two alternatives $\mathrm{A}$ and $\mathrm{B}$, and assuming there is no ties in utilities; a rational individual chooses alternative $A$ if and only if $U_{A}>U_{B}$ and vice versa. In the 
events of illness, the individual " $I$ " is assumed to maximize utility $(\mathrm{U})$ conditional on the consumption of health provided by provider " $\mathrm{j}$ ", subject to the budget constraint and health production function" [23, 24].

$$
\begin{aligned}
& \text { Max Uij }=\mathrm{U}(\mathrm{Hij}, \mathrm{Cij})+\mathrm{e}_{\mathrm{ij}}, \\
& \begin{aligned}
\text { Subject to }: \mathrm{mi}= & \text { Pij } \\
& + \text { Pc Cij (budget constraint) }
\end{aligned} \\
& \mathrm{Hij}=\mathrm{Ho}+\mathrm{Qj}(\mathrm{X}, \mathrm{Z}) \text { (Health Production), }
\end{aligned}
$$

Where:

Hij -Is the post- treatment health status of the individual treated by provider $j$.

Cij -Is the consumption level composite goods after choosing provider $j$.

Eij- Is the random error term that captures the notion that efficacy of medical care is not perfect.

mi- Is the total income of the household.

Pij -Is the price of medical treatment from provider $j$. It includes both money and time costs.

Pc -Is the price of the composite consumption goods.

Ho -Is the initial health status of the individual.

Qj- Is the improvement in health status of the individual after the treatment by provider $j$.

The improvement in health status of an individual (Qj) is a function of a vector of individual characteristics $(\mathbf{Z})$ provider characteristics $(\mathbf{X})$ [25]. It follows that individual $i$ will maximize the unconditional utility function $\left(\mathrm{U}^{*}\right)$ which is given by

$$
\mathrm{Uj}^{*}=\max (\mathrm{Ui} 1, \mathrm{Ui} 2,---, \mathrm{Uij}+1)
$$

Where.

Uij Is the utility function of care from provider $j=1,2$, ,$--- j+1$.

Solution to eq. (4) provides the health care alternative that yield the highest utility and to be chosen by an individual $[25,26]$. Normalizing Pc to one and substituting eqs. (2) \& (3) into eq. (1), we will get conditional utility function of provider $j$ that can be written as

$$
\mathrm{Uij}=\mathrm{U}(\mathrm{Ho}+\mathrm{Qij}(\mathrm{X}, \mathrm{Z}), \mathbf{m i}-\mathrm{Pij})+\mathrm{eij}
$$

When the above utility function is quasi linear in Hij and $\mathrm{Cij}$ and these components are greater than zero, the indirect utility function is given by:

$$
\mathrm{V}=\mathrm{V}(\mathrm{P}, \mathrm{H}, \mathrm{Q}(\mathrm{X}, \mathrm{Z}), \mathbf{m})+\mathrm{e}
$$

Equation (6) is the reduced form of the indirect utility function of alternative $j$ and in most of the literature; it forms the basis of estimating health care demand functions. It conveys the message that the demand for health care depends on price, health status, the improvement in health status and individual and providers' characteristics [27].
The indirect utility obtained by a patient from a given clinic, according to [28], can be derived from a multiplicative indirect utility specification and is given as:

$$
\ln \mathrm{V}=\mathrm{V}^{*}+\mathrm{e}_{\mathrm{ij}}
$$

Where $\mathrm{V}$ denotes the indirect utility gained by the individual $\mathrm{i}(i=1,2, \ldots)$ from choosing $\mathrm{j}$ clinic type $(j=1,2, \ldots, J)$ and $e$ is the random error term.

Furthermore, $\mathrm{V}$ can be decomposed into

$$
\mathrm{V}_{\mathrm{ij}}=\mathrm{X}_{\mathrm{ij}} \beta+\mathrm{z}_{\mathrm{i}} \alpha_{\mathrm{i}}
$$

Where: $X(=\ln X 1, \ln X 2, \ldots, \ln X \mathrm{k})$, the X k's (k $=1,2, \ldots, \mathrm{k}$ ) are alternative (provider type) specific observable exogenous variables;

$\mathrm{B}$ is a $\mathrm{K} \times 1$ vector of unknown parameters to be estimated;

$\mathrm{Zi}=(\ln \mathrm{Zi} 1, \ln \mathrm{Zi} 2,---, \ln \mathrm{ZiG})$, the ZiG's $(\mathrm{g}=1,2$, -.--, G) are individual (patient) specific observable exogenous variables;

$\alpha_{\mathrm{i}}=$ is a Gx1 vector for unknown parameters to be estimated [28].

Assuming IID (independently identically distributed) $\log$-Weibull distribution for the disturbances $\mathrm{e}_{\mathrm{ij}}$, the $\mathrm{P}_{\mathrm{ij}}$, the probability that individual $i$ will choose clinic type $\mathrm{j}$, according to [26], is

$$
\mathrm{P}_{\mathrm{ij}}=\frac{\exp \left(\mathrm{V}_{\mathrm{ij}}{ }^{*}\right)}{\sum_{j=1}^{j} \exp \left(V i j^{*}\right)}
$$

Substituting eq. (8) in to Eq. (9), the probability that individual $i$ will choose clinic type $j$ is rewritten as

$$
\mathrm{Pij}=\frac{\exp \left(\mathrm{X}_{\mathrm{ij}} \beta+Z_{\mathrm{j \alpha i}}\right)}{\sum_{j=1}^{j} \exp \left(\mathrm{Xij}_{\beta} *+\mathrm{Zi \alpha i}\right)}
$$

Assuming Yi be a random variable indicating the choice made, the probability of choosing provider $j$, according to [27] and [29], is:

$$
\operatorname{pij}=\operatorname{prob}(\mathrm{Yi}=j)=\frac{\exp \left(\mathrm{X}_{\mathrm{ij}} \beta+\mathrm{Z}_{\mathrm{j \alpha i}}\right)}{1+\sum_{j}^{j} \exp \left(\mathrm{X}_{\mathrm{ij}} \beta *+\mathrm{Z}_{\mathrm{i \alpha i}}\right)}
$$

Furthermore the likelihood for this problem is $\operatorname{lnLi}=$ $\operatorname{Dij} \ln \operatorname{pr}(Y i=j)$, where Dij is a dichotomous variable that takes on the value 1 if individual $i$ chooses alternative $j$ (i.e., if $\mathrm{Yi}=\mathrm{j}$ ) and 0 if he/she do not choose it $[26,27]$ and [29].

\section{Estimation \& Variable}

The analysis for demand of health care provider choice in Tsegedie district, northern Ethiopia was carried out using the multinomial logit model. Estimation of the multinomial logit model specified in equation [29] above is undertaken 
using a statistical package called STATA. Model fitting was checked by maximum likelihood model, Multicollinearity was checked by Durbin-Watson that is the variable inflation factor.

The dependent variable is choice of specific health care providers. The alternative health care providers are Public health care providers, Private health care providers and self-treatment or not consulted modern care. Our response variable, health care provider choice is going to be treated as categorical under the assumption that the choice of health care provider has no natural ordering.

Health care provider choice

$$
=\left\{\begin{array}{c}
1 \text { if consulted public health care provider } \\
2 \text { if consulted private health care provider } \\
3 \text { if no consulted modern health care provider } \\
\text { (self-treatment) }
\end{array}\right.
$$

The independent variables include different attributes of the individual patient, socioeconomic and the health care providers.

\section{List and description of explanatory variables}

Agehhd = A continuous variable for the age of household head.

Agept $=$ A categorical variable $(1=<5$ years old, $2=>=5$ ) years old.

Male $=$ A nominal variable 1 for male and 2 for female.

EducaHHd2 = educational level of household head $(1=$ not educated, 2 primary, and secondary and above.

HHsize $=$ nominal variable $(1=<5$ and $2=>=5)$.

Marital $2=$ nominal categorical variable $(1=$ married, 2 not married, 3 divorced and 4 for widowed).

HHincome 2 household monthly income $(1=0$-1000birr, $2=1001-2500$ birr, $3=2501-4500$ birr and $4=4500$ birr).

Educapt 2 = educational; level of patient $(1=$ not educated, $2=$ primary school, and $3=$ secondary school and above).

Severity $2=$ nominal variable $(1=$ mild illness and $2=$ severe illness).

Sexpt $2=$ nominal variable $(1=$ male, $2=$ female $)$.

Costoftreat $2=$ categorical variable for cost of treatment in birr $(1=<50,2=50-100,3=201-300$ and $4=>300$.

Qualiofser2 $=$ perceived quality of treatment categorical $(1=$ poor and $2=$ good $)$.

DistantoHF = continuous variable the nearest health facility, in kilometers.

The study utilized community-based cross-sectional study design with quantitative data collection method. The study population included all households experienced illness within 4 weeks prior to the study period in the community of Tsegedie woreda, Northern, Ethiopia. Patients admitted for treatment during the data collection period were excluded from the study, may not give reliable information as far as they did not finish their treatment for measuring quality of treatment outcome.

The sample size was calculated using single population proportion formula with the following assumptions: proportion 50\%, which was appropriate to get maximum sample size than the sample size calculated using Epi-info software considering $80 \%$ power. Using $5 \%$ margin of error at $95 \%$ confidence level, the sample size was 423 after considering $10 \%$ non-response rate. All kebeles of the woreda were included in the study after 1 month of census was done and 2189 patients were found. Therefore, 423 patients were selected using systematic random sampling technique after proportional allocation for each kebelle has been done. The independent variables were included from similar studies conducted elsewhere [24, 30-32].

The questionnaires were prepared by reviewing relevant literatures and adapting from previously done articles [30]. Pre- test was done on $10 \%$ of the subjects outside the study area at Welkaite district. Data were collected by pre-tested, pre-coded and interviewer-administered questionnaires. The collected data were cleaned, coded, entered into Epi-info version 7 software, transferred, and analyzed using STATA computer soft ware package version 11. Summary statistics of socio demographic variables were presented using frequency tables and graphs. The data analyzed using multinomial logistic regression to determine the effect of various factors on the outcome variable. Variables were entered into multiple logistic and multinomial logit regression models to control confounding effect.

The results were presented in the form of tables, figures and text using frequencies and summary statistics such as standard deviation, mean, and percentage to describe the study population in relation to relevant variables. The degree of association between dependent and independent variables were assessed using log odds ratio with $95 \%$ confidence interval and $p$-value 0.05 .

The study was reviewed and approved by Institution Research Review Board of, Institute of Public Health, College of Medicine and Health science, and University of Gondar. Official letter of permission was also obtained from Tigray Regional Health Bureau and Tsegedie Health Office. The purpose and the importance of the study were orally explained and written consent was obtained from each participant. Moreover, confidentiality of the information was assured by using anonymous questionnaires and by keeping the data in a secured place.

\section{Results}

A total 423 households were participated in the study with a response rate of $98 \%$. Majority of household heads 289(69.14\%) were males and 327(78.2\%) were Tigrian in ethnicity. More than $90 \%$ of households were orthodox Christian. 
About 285 (68.2\%) of respondents had four or more family members and the mean of family size was four members $(\mathrm{SD} \pm 2.7)$. More than half $219(52 \%)$ of the respondents were illiterates, and 177 (42.3\%) were farmers in occupation and $91(21.7 \%)$ were daily laborers. Concerning marital status majority $285(68.2 \%)$ of the household heads were married (Table 1).

The frequency table below sows that more than half 106 (51.2\%) of patients, whose household heads with no education consult medical care in the public health care provider. Nevertheless, 76 (66\%) of patients whose household heads were with no education did not Consult medical treatment (Table 2).

Households were divided in to four quartile representing income group ranging from quartile one (lowest income) to quartile four (highest income) based on stated monthly income. The result survey revealed that the higher household income associated with higher probability of seeking medical treatment in times of illness. Concerning to the choice of health care provider, households preferences seems to shift from public health facilities to those of private ones as there income level rises, especially when we compare with the lowest income group $(p=0.033)$ (Table 3).

Table 1 Socio-demographic characteristics of households having ill/injured member of the family in the community of Tsegedie woreda, northern Ethiopia, April, $2016(n=418)$

\begin{tabular}{lll}
\hline Variables & Description & Number (\%) \\
\hline Sex of household head & Male & $289(69.1)$ \\
& Female & $129(31.9)$ \\
Ethnicity: & Tigray & $327(78.2)$ \\
& Amhara & $91(22.8)$ \\
Religion: & Orthodox & $387(92.6)$ \\
& Muslim & $29(6.9)$ \\
Marital status: & Others & $2(0.5)$ \\
& Married & $286(68.4)$ \\
& Not married & $32(7.7)$ \\
& Divorced & $80(19.1)$ \\
& Widowed & $20(4.8)$ \\
Occupational status of HHd: & Farmer & $177(42.3)$ \\
& Merchant & $57(13.6)$ \\
& Civil servant & $45(10.8)$ \\
& Daily laborer & $108(25.8)$ \\
& Private employed & $27(6.5)$ \\
& Housewife & $4(0.9)$ \\
Educational status of HHd: & No formal education & $219(52.4)$ \\
& Primary school & $128(30.6)$ \\
& Secondary school & $38(9)$ \\
& Above secondary school & $33(7.9)$ \\
\hline
\end{tabular}

Table 2 Health care provider chosen by education level of household head and Patient, at Tsegedie woreda, northern Ethiopia, April 2016

\begin{tabular}{llll}
\hline \multicolumn{4}{c}{ Health care provider chosen } \\
\cline { 2 - 4 } & Public & Private & No-care \\
\hline Household head educational status & & Number (\%) & Number (\%) \\
No formal education & $106(51.2)$ & $38(39.6)$ & $75(65)$ \\
Primary & $66(31.8)$ & $36(37.8)$ & $26(22.6)$ \\
Secondary & $15(7.2)$ & $13(13.5)$ & $10(8.7)$ \\
Above secondary & $20(9.7)$ & $9(9.4)$ & $4(3.5)$ \\
Educational status of patient & $106(51.2)$ & $41(42.7)$ & $76(66)$ \\
No formal education & $65(31.4)$ & $36(37.5)$ & $24(20.9)$ \\
Primary & $21(10.1)$ & $13(13.5)$ & $13(11.30)$ \\
Secondary & $15(7.2)$ & $6(6.50)$ & $2(1.70)$ \\
Above secondary &
\end{tabular}

Cross tabulation of the responses indicates that, given the type of illness that made patients visit physician, an increase in cost of treatment cause a decline in the number of patients who consulted public health care provider, whereas the for private health care provider first increase then decline. The result suggests that an increase in cost of treatment may improve the probability of consulting private health care provider relative to public provider. This indicates that presence of correlation between better quality and higher cost of treatment in private health care provider $(p<0.0001)$.

Concerning to the perceived quality of health care, about $86.5 \%$ and $13.5 \%$ of the respondents judged the quality of public health care providers as good and poor respectively. Similarly, the perceived quality of the private health care providers was good $(94.7 \%)$ and poor $(5.3 \%)$.

The study revealed that 303(72.5\%) (95\%CI; 63.8, 81.6) of the study participants consulted modern health care

Table 3 Medical care seeking behavior and provider related choice by income group (asset), at Tsegedie woreda, northern, Ethiopia April 2016

\begin{tabular}{llllll}
\hline \multirow{2}{*}{ Income quartiles in birr } & \multicolumn{3}{l}{ Option chosen } & Total \\
\cline { 3 - 5 } & & Public & Private & Not treated & \\
\hline 0-1000 & Count & 86 & 34 & 58 & 178 \\
& \% within income group & 48.2 & 19.1 & 32.8 & 100 \\
1001-2500 Count & 78 & 29 & 39 & 146 \\
& \% within income group & 54.2 & 20 & 26.7 & 100 \\
2501-4500 & Count & 26 & 19 & 9 & 54 \\
& \%within income group & 48.1 & 35 & 16.6 & 100 \\
$>4500$ & Count & 15 & 16 & 9 & 40 \\
& \%within income group & 39.4 & 40 & 23.6 & \\
Total & & 205 & 98 & 115 & 418 \\
\hline
\end{tabular}


service. Among those who visited modern health care facilities, 49.5 had visited public health care providers. However, abound $27.5 \%$ of the respondents did not visit modern health care services. Majority of the patients who consulted public owned health care providers explained the availability of drugs, lower cost of treatment and nearness of the providers as their main reasons for consulting them. However, short waiting time and quality of treatment were the main reasons for choosing private health care providers.

\section{Factors associated with demand of health care service}

The dependent variable used was health care choice represented by "Type", while the independent variables are individual, household, and access. The coefficients of each variable reflect the effect of a change in each of the variables on the probability that the individual will consult medical care and choose a certain provider relative to no-care (self-treatment).

The multinomial logit of being educated household head relative to less educated household head is 0.079 ( $95 \% \mathrm{CI}$ $0.966,1.124)$ and $0.966(95 \% \mathrm{CI} 0.050,3.438)$ units higher to visit public health care provider and private health care provider to self treatment respectively, given all other predictor variables in the model are held constant.

Regarding to severity of illness, as the severity of illness increases, the $\log$ odds of consulting public and private health care providers increased by $1.27(95 \% \mathrm{CI} 0.74,1.80)$ and $1.82(95 \% \mathrm{CI} 1.45,2.502)$ respectively in favor of self treatment.

As the perceived quality of treatment increases, the log odds of opting to the public and private health care providers increased by $0.989(95 \% \mathrm{CI} 0.472,1.507)$ and $1.154(95 \%$ CI $0.624,1.683)$ times relative to self-treatment respectively. Similarly, as the cost of treatment of private health care provider increases; the multinomial logit of consulting private health care providers expected to decrease by 2.510 times relative to the self-care treatment.

Age of patient is statistically significant and negatively associated with health care demand. If the age of the patient were to increase by one year, the multinomial log-odds of consulting public health care provider relative to self- treatment would be expected to decrease by $0.63(95 \% \mathrm{CI}-1.24$, -.008) times. Similarly, as distance to health facility increases by $1 \mathrm{~km}$, the probability to opt public and private health care providers would be expected to decrease by 0.13 and 1.96 times respectively relative to self-treatment (Table 4).

\section{Discussion}

The finding of this study showed that $72.5 \%$ patients consulted modern health care. This finding is almost similar with the studies conducted in Mekelle town (79\%) [33] and Kenya (70\%) [30]. This result shows that the demand of patients for modern health services in Northern Ethiopia is low. This implies, still, significant number of patients either is not getting health services or is consulting traditional healers. The observed low demand for health care might be due to community-based health insurance or other prepayment schemes are not yet implemented in the community.

The multinomial logit regression analysis revealed that, having higher educational level (secondary school and above) of household heads increases the probability of seeking modern medical care than with no education. This finding was consistent with studies conducted in Tanzania [5], Kenya [34] and urban Ethiopia [35]. This might be because the educated people may have better awareness about the importance of modern medicine. Similarly, perceived severity of illness was found to be another factor statistically associated with demand for health care service. This study revealed that as the duration of illness increases, the probability of consulting modern health care service increased related to mild illness. This result is supported with the studies conducted in urban Ethiopia [35] and rural Ethiopia [36]. Patients' perception regarding the seriousness of illness plays a significant role in their decision of consulting in both public and private modern medical treatment related to mildness of illness.

The perceived quality of health care services was statistically and significantly associated with the patients' demand for health care services. As the quality of treatment increases, the probability of opting to public and private health care providers increases relative to self-treatment. This finding is similar with the studies conducted in Uganda [37], Kenya [34] and rural Tanzania [5]. This might be due to the reason that high-perceived quality of care in the public, private health care facilities have the potential to attract patients, and it is correlated with high patient satisfaction.

Increasing user charges decreases the likelihood of seeking health care from the modern health care provider relative to self-treatment. The result of this study is consistent with studies conducted in urban Ethiopia [35],Kenya [38] and cote D'Ivore [39]. This might be because demand for health care is negatively affected by lower income and high price of health care. However, this result is not supported by a study conducted in Philippines [40]. The observed difference might be due to the difference in the implementation of financial protection mechanisms and socio-economic level between the two countries.

Distance to health facilities has statistical and significant association with demand for health care services. The multinomial logit model showed that as distance to health facility increases, the probability to opt self-treatment increases. This finding concurs with the study conducted In Kenya [41], Coted'ivore [39] and Benin [4]. This may 
Table 4 The log-odds for Private and public health care providers relative to not treated Multinomial Logistic Regression Results of patients at Tsegedie woreda, northern Ethiopia, 2016

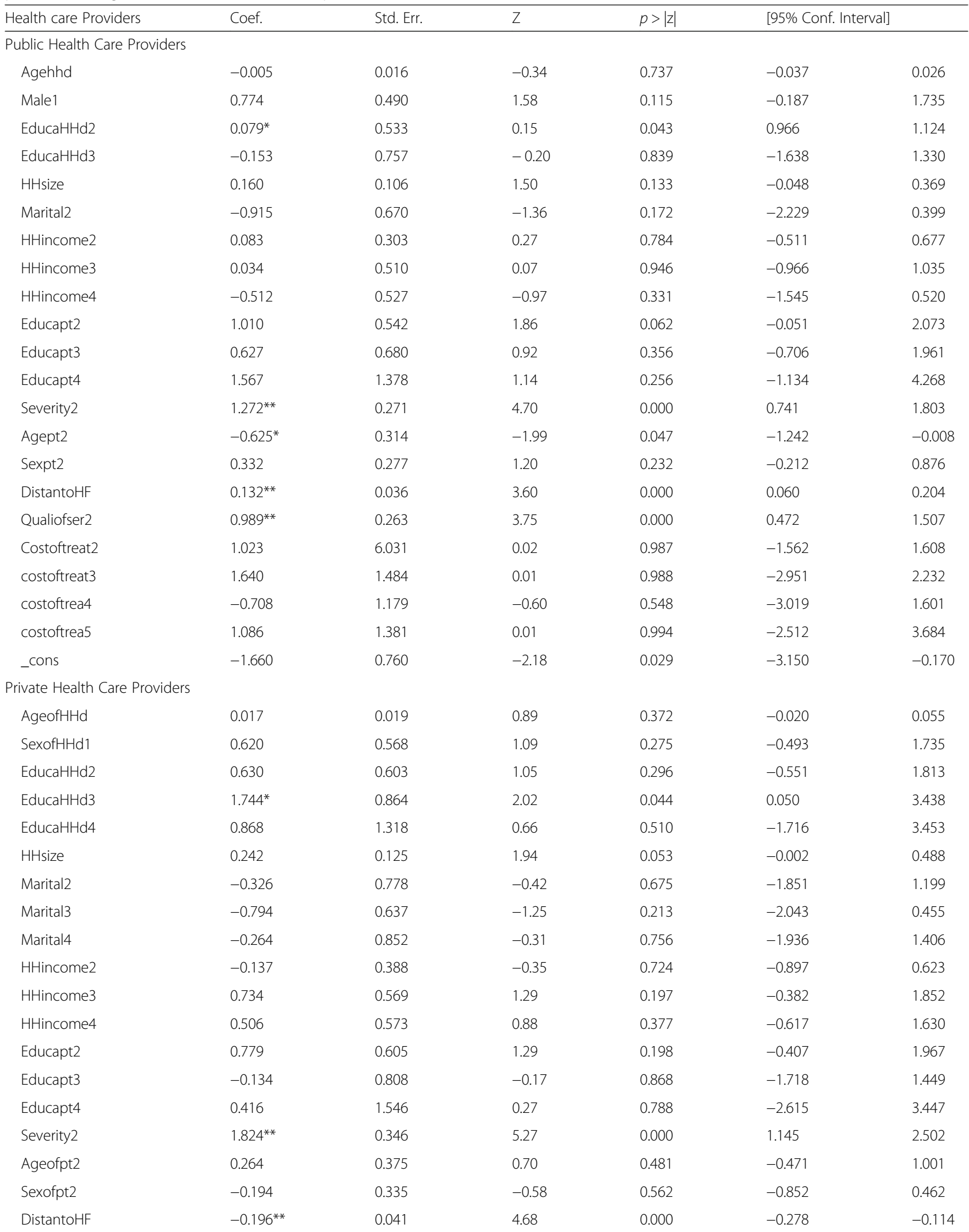


Table 4 The log-odds for Private and public health care providers relative to not treated Multinomial Logistic Regression Results of patients at Tsegedie woreda, northern Ethiopia, 2016 (Continued)

\begin{tabular}{lllllll}
\hline Health care Providers & Coef. & Std. Err. & $Z$ & $p>|z|$ & {$[95 \%$ Conf. Interval] } \\
\hline Qualiofser2 & $0.989^{* *}$ & 0.263 & 3.75 & 0.000 & 0.472 & -1.886 \\
costoftrea2 & 1.699 & 6.031 & 0.02 & 0.987 & 0.987 & -2.970 \\
costoftrea3 & 1.621 & 1.485 & 0.02 & 0.907 & -4.702 & -285 \\
Costoftrea4 & $-2.510^{*}$ & 1.118 & 2.24 & 0.25 & -0.317 \\
costoftrea5 & 1.948 & 1.381 & 0.01 & 0.992 & -6.649 & 3.546 \\
_cons & -5.072 & 0.982 & -5.17 & 0.000 & -3.148 \\
\hline
\end{tabular}

Not treated (base outcome) ** significant at $1 \%$ and less, ${ }^{*}$ significant at $5 \%$ and less. $\mathrm{HHd}=$ household head

The variables were statistically predicted at; LR chi2 $(44)=122.01$ Log likelihood $=-372.8138$, Pseudo R2 = 0.1406

be paying some cost to travel to the source of treatment as opposed to seeking self-treatment.

This study has limitations particularly due to recall bias because the patients were expected to tell us a one-month history of illness and related costs. However, we have made tried to associate with special events to reduce the possible recall bias.

\section{Conclusion}

This study showed that more than one-fourth patients did not demand modern care. Educational status of household head, distance to health facility, cost of treatment, severity of illness, and quality service were independent predictors of demand for health care service. The Regional Health Bureau, Woreda Health Office and other relevant stakeholders need to design and implement prepayment schemes such as community based health insurance to increase the patients demand for modern health care services. Similarly, the Woreda Health Office needs to work to improve the awareness of patients on modern health care services.

\section{Abbreviations \\ Cl: Confidence Interval; EDHS: Ethiopian Demographic and Health Survey; FIML: Full Information Maximum Likelihood; FMOH: Federal Ministry of Health; HSDP: Health Sector Development Programme; IIA: Independent Irrelevant Alternatives; MLM: Multinomial Logit Model; NGOs: Non-Government Organizations; NHA: National Health Account; OR: Odds Ratio; WHO: World Health Organization}

\section{Acknowledgments}

We are very thankful to University of Gondar for the approval of the ethical issue and its technical and financial support. Our special thanks and sincere appreciation also go to Regional Health Bureau, Tsegedie woreda workers, supervisors, data collectors and study participants.

\section{Funding}

This is part of a master thesis funded by University of Gondar. The preliminary findings of this study were presented at Institute of Public Health, University of Gondar. After incorporating the comments, the authors have prepared this manuscript for publication at BMC health services research. The funders had no role in study design, data collection and analysis, decision to publish, or preparation of the manuscript.

\section{Authors' contributions}

TW designed the study, developed data collection tools, performed the analysis and interpretation of data and drafted the paper. MG, MM, HG, BA, AT and YZ participated in the development of the study proposal, analysis and interpretation, revised drafts of the paper, prepared and revised the manuscript. All authors read and approved the final manuscript.

Ethics approval and consent to participate

The study was approved by the ethical review committee of the Ethical Review Board of Institute of Public Health, College of Medicine and Health Science, University of Gondar with the reference number 2827/02/2016. Permission letters were obtained from Regional Health Bureau and district health office. Written consent from study participants were also obtained after explaining the purpose of the study and confidentiality was assured using coding system; questionnaires did not have any personal identifiers.

Competing interests

All authors declare that they have no competing interest.

\section{Publisher's Note}

Springer Nature remains neutral with regard to jurisdictional claims in published maps and institutional affiliations.

\section{Author details}

${ }^{1}$ Department of Health system, School of Public Health, College of Health Sciences, Mekelle University, Mekelle, Ethiopia. ${ }^{2}$ Department of human nutrition development, Institute of Public Health, College of Medicine and Health Sciences, University of Gondar, Gondar, Ethiopia. ${ }^{3}$ Department of Public Health Emergency Management, Institute of Tigray Health Research, Mekelle, Ethiopia.

Received: 4 January 2018 Accepted: 22 August 2018

Published online: 10 September 2018

\section{References}

1. Asteraye N. Determinants of Demand for Health Care Services and their Implication on Health Care Financing: The Case of Bure Town1. Ethiopian J Econ. 2002;11(1).

2. Bello R. Determinants of demand for traditional method of health care services in Osun state: Nigeria. Ind J Soc Dev. 2005;5:203-17.

3. Andersen R, Newman JF. Societal and individual determinants of medical care utilization in the United States. The Milbank Memorial Fund Quarterly. Health Soc. 1973:95-124.

4. Bolduc D, Lacroix G, Muller C. The choice of medical providers in rural Benin:a comparison of discrete choice models. J Health Econ. 1996;15:477-98.

5. Sahn DE, Younger SD, Genicot G. The demand for health Care Services in Rural Tanzania. Oxf Bull Econ Stat. 2003;65(2):241-59.

6. Valongueiro S. Demand for health Care in Brazil: a preliminary analysis by regions. Universidade do Texas/PRC.

7. Poullier JP, Hernandez P, Kawabata K, Savedoff DW. National health accounts: concepts, data sources and methodology. World Health Organization; 2002. 
8. WB. World development report. Making services work for poor people New York. In: Oxford university press; 2004.

9. Grossman M. On the concept of health capital and the demand for health. J Pol Econ. 1972:80:223-55.

10. A. How poverty affects the health status and the health care demand behavior of households? The case of rural Ethiopia. Centre for development research (ZEF), university of Bonn.

11. Rogers, Richard, Hummer, Robert NC. Perceived Health Status and mortality. In: Living and dying in the USA Academic Press; 2000. p. 175-95.

12. Anyanwu JC. Demand for health care institutions' services: evidence from malaria fever treatment in Nigeria. Afr Dev Rev. 2007;19(2):304-34.

13. Gaddah M, Munro A, Quartey P. The demand for public health care and the progressivity of health care services in Ghana. Afr Dev Rev. 2015 Jun;27(2):79-91.

14. Arega T, Kello DA. The Demand for Curative Health Care in Jimma Town: Choosing Between Health Care Providers. VDM Publishing; 2010.

15. Becker GS. Health as human capital: synthesis and extensions. Oxford Econ Papers. 2007;59:379-410.

16. Schultz TP. Health human capital and economic development. J Afr Economies. 2010;19:iii12-80.

17. Grossman M. Front matter, the demand for health: a theoretical and empirical investigation. InThe demand for health: a theoretical and empirical investigation 1972 Jan 1 (pp. 20-0). NBER.

18. Fuchs VR. Reflections on the socio-economic correlates of health. J Health Econ. 2004;23(4):653-61.

19. Mwabu G. Health economics for low-income countries. In: Schultz TP, Strauss J, editors. Handbook of development economics Volume 4. Amsterdam: Elsevier/North-Holland; 2008. p. 3305-74.

20. Z DWSR. Patients' Perception of health care quality, satisfaction and behavioral intention: an empirical study in Bahrain. Int J Bus Soc Sci. 2012;3(18):131-41.

21. Gertler $P, J \vee d G$. The willingness to pay for medical care: evidence from two developing countries. Baltimore: Johns Hopkins University Press; 1990.

22. Scott JL. Regression Models for Categorical and Limited Dependant Variables. USA: SAGE publications, Inc; 1997.

23. Puig-Junoy, Jaume, and M Saez, Martinez-Garcia E. Health care provider choice in the case of patient initiated contacts: an extended version ofdiserete choice model demand. pmpt/uptgen/308html. 2002.

24. Arega T. The Demand for Curative Health Care in Jimma Town, Choosing Between HealthCare Providers. 2003.

25. Lohlien D, Jütting J, Wahrheim P. Provision of public goods in transition process:empirical evidence on access to health care in rural regions of Russia. University of Maryland: IRIS; 2002.

26. Green WH. Econometric analysis. 3rd edn. In: Prentice-hall international Inc; 1997.

27. li M. The demand for medical care evidence from urban areas in Bolivia. The living standard measurement study, working paper no.123. Washington, DC: The World Bank; 1993.

28. Mwabu GM. Health care decisions at the household level: results of a rural health survey in Kenya. In: Social science and medicine 22. London: Pergamon Press Ltd; 1986.

29. Maddala GS. Limited-dependent and qualitative variables in econometrics. Cambridge university press; 1986.

30. Awiti JO. Poverty and health care demand in Kenya. BMC Health Serv Res. 2014;14(1):1-17.

31. Amaghionyeodiwe LA. Determinants of the choice of health care provider in Nigeria. Health Care Manag Sci. 2008 Sep 1;11(3):215-27.

32. Victoor A, Delnoij DM, Friele RD, Rademakers JJ. Determinants of patient choice of healthcare providers: a scoping review. BMC Health Serv Res. 2012;12(1):272

33. Belay M. Determinants of Demand for Health Care Services in Mekelle City (Doctoral dissertation, Mekelle University).

34. Mwabu G, Wang'ombe J, Nganda B. The demand for medical care in Kenya. Afri Dev Rev. 2003;15:439-53.

35. Guda A. Challenges of healthcare financing: economic and welfare effects of user fees in urban Ethiopia (Doctoral dissertation, MSc Thesis, Addis Ababa University, School of Economics).

36. Lemma TD. Demand for traditional health care services in rural Ethiopia. Asian J Res Bus Econ Manag. 2013;3(3):31-45.

37. Ea K. Demand for health care services in Uganda: implications for poverty reduction. Makerere University: Economic policy research center; 2004
38. MK M. The determinants of health-seeking behavior in a NAIROBI slum. KENYA Eur Sci J Ed. 2013;9(8):1-14.

39. Cisse A. Analysis of health care utilization in Côte d'Ivoire. AERC; 2006.

40. Akin JSC, Griffin DK, Guilkey BMP. Demand for PrimaryHealth Services in the Bicol Region of Philippines. Econ Dev Cult Chang. 1986;34(4):755-78.

41. Muriithi MK. The demand for health care in Nairobi slum; European Scientific Institute. European Scientific Institute. August, 2013.
Ready to submit your research? Choose BMC and benefit from:

- fast, convenient online submission

- thorough peer review by experienced researchers in your field

- rapid publication on acceptance

- support for research data, including large and complex data types

- gold Open Access which fosters wider collaboration and increased citations

- maximum visibility for your research: over $100 \mathrm{M}$ website views per year

At BMC, research is always in progress.

Learn more biomedcentral.com/submissions 